\title{
Preparation and Characterization of a Bioartificial Polymeric Material: Bilayer of Cellulose Acetate-PVA
}

\author{
Andrés Bernal-Ballén, ${ }^{1}$ Ivo Kuritka, ${ }^{2}$ and Petr Saha ${ }^{2}$ \\ ${ }^{1}$ Grupo de Investigación en Ingeniería Biomédica, Vicerrectoría de Investigaciones, Universidad Manuela Beltrán, \\ Avenida Circunvalar, No. 60-00, Bogotá, Colombia \\ ${ }^{2}$ Centre of Polymer Systems, University Institute, Tomas Bata University in Zlin, Třída Tomase Bati 5678, 76001 Zlin, Czech Republic
}

Correspondence should be addressed to Andrés Bernal-Ballén; andres.bernal@docentes.umb.edu.co

Received 3 March 2016; Accepted 4 May 2016

Academic Editor: Arthur J. Ragauskas

Copyright (C) 2016 Andrés Bernal-Ballén et al. This is an open access article distributed under the Creative Commons Attribution License, which permits unrestricted use, distribution, and reproduction in any medium, provided the original work is properly cited.

\begin{abstract}
A new bioartificial polymeric material consisting of a bilayer of cellulose acetate and poly(vinyl alcohol) was successfully obtained by casting method. The material was characterized by Fourier transform infrared spectroscopy, contact angle, scanning electron microscopy, differential scanning calorimetry, gas permeability, water vapor permeability, and mechanical properties. The characterization indicates that two distinct and well-differentiated surfaces were achieved without detriment to the bulk properties. The interaction between natural and synthetic polymers indeed enhanced the gas permeability as well as the water vapor permeability in comparison to the original components, although mechanical properties were not substantially boosted by the combination of both. Moreover, beyond the interface, there were no detected interactions between the polymers as can be evidenced by the presence of a unique $T_{g}$ in the bilayer. The amalgamation of the relatively good mechanical properties with the two differentiated surfaces and the improvement of the permeability properties could indicate the potential of the material for being used in medicine.
\end{abstract}

\section{Introduction}

A sight to the past evidences that, during the last two decades, synthetic and natural polymers have been separately used as potential biomaterials [1]. Among biomaterials, bioartificial polymeric materials (BAPM) have gained an important place in the field of biomaterials in recent times. They represent a new class of polymeric constituents based on blends of synthetic and natural polymers, designed with the purpose of producing new materials with enhanced properties with respect to the individual components. In this matter, cellulose acetate (CA) which is an abundant natural fiber resource with an excellent tensile strength [2] is widely used in oral pharmaceutical products and is regarded as a nontoxic, nonirritant, and biodegradable material [3]. Among its wide array of applications, cigarette filters, high absorbent diapers, semipermeable membranes for separation processes and fibers, and films for biomedical utilities as well as the textile and the biomedical domain and mats for transdermal drug delivery can be included [4]. In addition, a long term antimicrobial effect for wound healing application was recently reported [5]. As a synthetic polymer, poly(vinyl alcohol) (PVA) is worth mentioning because it is one of the world's largest volumes synthetic resins produced due to its excellent chemical resistance, physical properties, biocompatibility, and complete biodegradability indeed [6]. PVA is furthermore used in industry due to its high capability of water absorption [7] and its excellent film-forming properties. As a promising biomaterial, diverse researches have been focused on the application of PVA in biomedical and pharmaceutical fields. High mechanical strength, rubber-like elasticity, low-protein adsorption, high water content, and no adhesion to surrounding tissues make PVA gels a potential material for soft contact lenses, soft tissue replacements, articular cartilage, intervertebrate disc nuclei, transcatheter arterial embolization agent, artificial skin, and vocal cord [8-12]. PVA has been used in blends and composites with natural polymers since its 
TABle 1: Prepared films.

\begin{tabular}{|c|c|c|}
\hline Number & Sample & Description \\
\hline 1 & PVA & A PVA film obtained from a $5 \mathrm{wt} \%$ water solution \\
\hline 2 & $\mathrm{PVA}+\mathrm{ADD}$ & $\begin{array}{l}\text { A PVA film obtained from a } 5 \mathrm{wt} \% \text { water solution }+\mathrm{GA}(0.25 \mathrm{wt} \%)+\mathrm{LA}(15 \mathrm{wt} \%)+\mathrm{HCl}(1.2 \mathrm{wt} \%) \text { related to the } \\
\text { total amount of the polymer }\end{array}$ \\
\hline 3 & $\mathrm{CA}$ & A CA film obtained from a $10 \mathrm{wt} \%$ acetone solution \\
\hline 4 & $\mathrm{CA}+\mathrm{ADD}$ & A CA film obtained from a $10 \mathrm{wt} \%$ acetone solution + PEG (4.5 wt $\%$ ) \\
\hline 5 & Bilayer & $\mathrm{CA}+\mathrm{ADD}$ and on it PVA + ADD \\
\hline
\end{tabular}

hydrophilic and filming character allows for some degree of compatibility with functional natural polymeric materials. The biodegradability and water solubility of PVA ensure its easy degradation and elimination after use [13].

In order to overcome the poor biological performance of synthetic polymers and to enhance the mechanical characteristics of biopolymers, BAPM have been introduced. They should usefully combine the biocompatibility of the biological component with the physical and mechanical properties of the synthetics. The basic philosophy of BAPM is to smooth the interactions between synthetic and living systems creating a two-component material. Such material should behave better macroscopically than a fully synthetic material, with regard to the biological response of the host [1].

BAPM can be cast as films and a variety of potential applications have been targeted including dialysis membranes, wound dressing, artificial skin, cardiovascular devices, nerve guide channels, and implantable devices to release biologically active substances in a controlled manner. A further potential use may be found in orthopedic applications, for instance, bone graft substitutes [14, 15]. Recently, a BAPM composed of bilayer of collagen and PVA has been synthesized and the material exhibits viscoelastic features useful for being used in contact with living organisms [16]. Nonetheless, the use of bilayers within biomedical field is practically nonexistent and there are just few reports in the scientific literature.

For all the aforementioned reasons, bilayers can be therefore included into BAPM category and those systems present different surfaces properties. Despite the plethora of publications on cellulose in general and CA in particular and the broad use of PVA in medical field, the combination of the cited polymers presents a drawback in the research field and is still lacking studies which could contribute to making a comprehensive study of their interaction as bilayers systems. Indeed, according to our best knowledge, it is the first time that the BAPM consisting of CA-PVA is reported and characterized taking into consideration that the material could be an interesting window for use in biomedical field, including but not limiting to reducing fibrous adhesion.

\section{Materials and Methods}

Cellulose acetate (CA) was purchased from Aldrich Co., USA. Molecular weight $\left(M_{w}\right)$ was $30,000 \mathrm{~g} \mathrm{~mol}^{-1}$, acetyl content was $39.8 \mathrm{wt} \%$, and degree of substitution (DS) was
2.4. Poly(vinyl alcohol) (PVA, $M_{w} 47,000 \mathrm{~g} \mathrm{~mol}^{-1}$ ) with a degree of polymerization of 1,000 and $98 \%$ hydrolysis and a $50 \%$ water solution of glutaraldehyde (GA) were provided by Sigma Aldrich, The Czech Republic. Polyethylene glycol 400 (PEG) at analytical grade was supplied by Fluka, Germany, whereas lactic acid (LA) (analytical grade) was produced by Lachema, The Czech Republic; hydrochloric acid $\left(\mathrm{H}^{+}\right)$ (analytical grade) and acetone were supplied by Penta, The Czech Republic. All the reagents were used as they were received.

\subsection{Sample Preparation}

2.1.1. Single Layer. A $10 \mathrm{wt} \%$ solution of CA was prepared in acetone at room temperature by the slow addition of the polymer to the solvent under mild magnetic stirring using a Heidolph MR Hei-Standard magnetic stirrer with heating (Heidolph Instruments GmbH, Schwabach, Germany). PEG was added as a plasticizer at $4.5 \mathrm{wt} \%$, and the solution was stirred for 30 more min. The solution then underwent degasification using an ultrasonic cleaning unit (S80 Elmasonic, Elma $\mathrm{GmbH}$, with degasification function, Germany) and $0.5 \mathrm{~mL}$ per $\mathrm{cm}^{2}$ was poured on a glass Petri dish and allowed to dry in a no-air circulating oven for $24 \mathrm{~h}$ at $35^{\circ} \mathrm{C}$ [17].

An aqueous solution of PVA at $5 \mathrm{wt} \%$ was prepared by dissolving the polymer at $80^{\circ} \mathrm{C}$ for $6 \mathrm{~h}$ under continuous magnetic stirring heating (Heidolph Instruments $\mathrm{GmbH}$, Schwabach, Germany). Once the solution was obtained, GA at $0.25 \mathrm{wt} \%$ and hydrochloric acid at $1.2 \%$ related to the total amount of polymer were added as cross-linker agent and the solution was heated up to $80^{\circ} \mathrm{C}$ during $20 \mathrm{~min}$ as a crucial step in the cross-linking mechanism. Moreover, LA at $15 \mathrm{wt} \%$ related to the total amount of the polymer was used as plasticizer. The solutions were poured $\left(0.5 \mathrm{~mL}\right.$ per $\left.\mathrm{cm}^{2}\right)$ and cast on glass Petri dishes and allowed to dry at $35^{\circ} \mathrm{C}$ for 4 days in a no-air circulating oven. Table 1 summarizes, designs, and describes each sample.

2.1.2. Bilayers (Bioartificial Polymeric Material (BAPM)). A single layer of CA + ADD was obtained and dried, and the PVA + ADD solution was cast on it. The system was allowed to dry under the same conditions as for single layer films.

\subsection{Measurements}

2.2.1. Fourier Transform Infrared (FTIR). FITR spectroscopy analysis was carried out on NICOLET 6700 FTIR 
spectrometer device (Thermo Scientific, United States) equipped with attenuated total reflectance (ATR) accessory utilizing the Zn-Se crystal and software package OMNIC over the range of wavelengths from 4,000 to $600 \mathrm{~cm}^{-1}$ at room temperature under resolution $4 \mathrm{~cm}^{-1}$. Each spectrum represents 64 coadded scans referenced against an empty ATR cell spectrum.

2.2.2. Contact Angle: Surface Wettability Assessment. Wettability of the samples was evaluated by contact angle measurement. The sessile drop method was used for this purpose on a Surface Energy Evaluation (SEE) system equipped with a CCD camera (Advex Instruments, The Czech Republic). Deionized water, ethylene glycol, and diiodomethane were used as testing liquids at $25^{\circ} \mathrm{C}$ and $50 \%$ relative humidity. The droplets volume was set to $5 \mu \mathrm{L}$ for all experiments and a photo was taken immediately after the deposition of every drop. The contact angle value was an average of 10 independent measurements. The substrate surface free energy was evaluated by using the acid-basic model.

2.3. Scanning Electron Microscopy (SEM). Surface morphology of the films as well as the cross section of the BAPM was investigated by scanning electron microscope Vega II LMU (Tescan, Czech Republic), after coating with a thin layer of gold/palladium by the sputter coater SC 7640 (Quorum Technologies, UK). The microscope was operated under high vacuum at an acceleration on voltage of $5 \mathrm{kV}$.

2.4. Differential Scanning Calorimetry (DSC). Calorimetric measurements were carried out in a DSC 1 calorimeter, Mettler Toledo (Greifensee, Zurich, Switzerland), under nitrogen flowing at a rate of $30 \mathrm{~mL} \mathrm{~min}{ }^{-1}$. The specimens were pressed in sealed aluminum pans. Heating cycle was performed in order to obtain glass transition temperature $\left(T_{g}\right)$ and melting temperature $\left(T_{m}\right)$. The samples were cooled down by nitrogen at an exponentially decreasing rate. The heating of the cycle was performed from 25 to $250^{\circ} \mathrm{C}$ at a rate of $20^{\circ} \mathrm{C} / \mathrm{min}$. $T_{g}$ was determined as the midpoint temperature by standard extrapolation of the linear part of DSC curves using Mettler Toledo Stare software and $T_{m}$ as the maximum value of the melting peak.

2.5. Gas Permeability. The experimental method to determine the permeability of a polymer is based on the principle that molecules could permeate a polymer film. The gas permeability test was performed by using the pressure difference gas permeation instrument (VAC-V1, Labthink Instrument Co., Jinan, China). A test specimen is mounted in a gas transmission cell to form a sealed barrier between two chambers. The lower-pressure chamber is evacuated at $20 \mathrm{~Pa}$ whereas the higher-pressure chamber has a pressure of $0 \mathrm{kPa}$ during 4 hours. A gas is introduced into the evacuated higher-pressure chamber at $106 \mathrm{kPa}$ and permeates into the lower-pressure chamber. Circular specimens with a diameter of $10 \mathrm{~cm}$ were cut although the tested area was $38.48 \mathrm{~cm}^{2}$ and the thickness was between 75 and $300 \mu \mathrm{m}$. The test was performed at $28^{\circ} \mathrm{C}$ and the relative humidity was $28 \%$.
Nitrogen, oxygen, air, and carbon dioxide were tested. The end of the test is judged by a proportion. If the rates of change of three consecutive data points are all smaller than the present proportion, system automatically terminates the test, calculates the slope of the change, and generates gas transmission rate (GTR) and permeability coefficient (Coef $P)$.

2.6. Water Vapor Permeability (WVP). The WVP was determined by desiccant method at $25^{\circ} \mathrm{C}$ and at $70 \%$ of relative humidity. The films were firmly fixed and sealed onto an open capsule with a diameter of $5 \mathrm{~cm}$ containing silica gel as desiccant. The systems were placed in climatic chamber (Challenge 250 from Angelantoni Industrie, Cimacolle, Italy) and they were weighed in an analytic balance (Denver Instrument SI-64, Göttingen, Germany). The water vapor transmission (WVT) was calculated using

$$
\mathrm{WVT}=\frac{\Delta m}{t * A}
$$

where $\Delta m$ is the mass change (kg), $t$ is the time (s), and $A$ is the membrane area $\left(\mathrm{m}^{2}\right)$. The value was calculated by linear regression from the points of weight gained and time in the constant rate period. From this data, WVP was obtained by

$$
\mathrm{WVP}=\frac{\mathrm{WVT} * l}{s *\left(\mathrm{RH}_{1}-\mathrm{RH}_{2}\right)},
$$

where $l$ is the membrane average thickness (m), $s$ is the saturation pressure $\left(3.159 \mathrm{kPa}\right.$ at $\left.25^{\circ} \mathrm{C}\right), \mathrm{RH}_{1}$ is the relative humidity of the conditioned chamber, and $\mathrm{RH}_{2}$ is the relative humidity inside the sample (both expressed as a fraction). Tests were performed in triplicate for single layers and four specimens (two per each side) for BAPM. The thicknesses were calculated as the mean of 5 different measurements across the specimen using a micrometer with the accuracy of $0.01 \mathrm{~mm}$.

2.6.1. Mechanical Testing. Young's modulus $(E)$, stress at break $(\sigma)$, and elongation at break $(\varepsilon)$ were tested on five specimens per sample using a rectangular test specimen specified in ISO 527-3 with a length of $100 \mathrm{~mm}$, width of $10 \mathrm{~mm}$, and thickness of about $0.200 \mathrm{~mm}$ [18]. The experiment was carried out using an Instron-type tensile testing machine (Testometric M350-5CT, Lincoln Close, Rochdale, England) and the rate was $50 \mathrm{~mm} / \mathrm{min}$. The test conditions are specified in ISO 291 [19]. The thickness of the samples was measured by a micrometer with the accuracy of $0.01 \mathrm{~mm}$.

\section{Results and Discussions}

3.1. Fourier Transform Infrared (FTIR). One of the main characteristics of the bilayers systems is that they present different surfaces on each side which implies enormous benefits as a promising material in the biomedical field. Therefore, FTIR spectroscopy can be considered as a pertinent identification criterion which provides information about those differences.

The PVA spectrum has been elucidated in different studies and in the present work the results are in accordance 


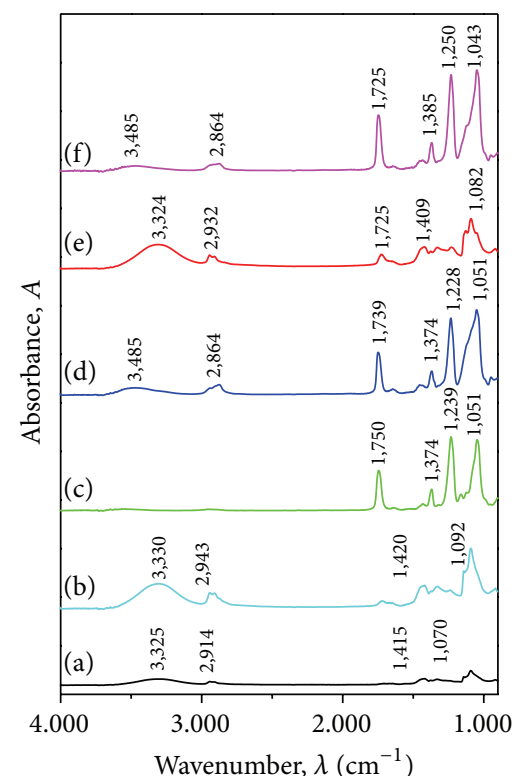

FIGURE 1: FTIR for the prepared films: (a) PVA; (b) PVA + ADD; (c) $\mathrm{CA}$; (d) CA + ADD; (e) BAPM PVA + ADD side; and (f) BAPM CA $+\mathrm{ADD}$ side.

with those reported in literature [16, 20-23] (Figure 1). There is a strong broad absorption band at $3,325 \mathrm{~cm}^{-1}$ which is characteristic for $\mathrm{OH}$ group. The bands at 2,947 and $2,914 \mathrm{~cm}^{-1}$ belong to saturated $\mathrm{C}-\mathrm{H}$ stretching, whereas the band situated at $1,415 \mathrm{~cm}^{-1}$ is related to $-\mathrm{CH} 2$ - bending [24]. The spectrum does not exhibit bands in the region of $1,700 \mathrm{~cm}^{-1}$, indicating the absence of acetate groups, an effect of the highly hydrolyzed PVA. The small peaks at 1,650 and $1,560 \mathrm{~cm}^{-1}$ can be attributed to conjugated diones or single carbonyls in conjugation with $\mathrm{C}=\mathrm{C}$ double bonds in solid state [23, 25-27]. The C-O stretching modes and strong dependency of its intensity on crystallinity degree of the solid PVA material were observed at $1,137 \mathrm{~cm}^{-1}[28,29]$. Other authors [30, 31], however, have reported this band as a manifestation of $\mathrm{C}-\mathrm{O}-\mathrm{C}$ in ether bridges. The bands at 1,415 and $1,329 \mathrm{~cm}^{-1}$ can be attributed to combination frequencies of $\mathrm{CH}$ and $\mathrm{OH}$ [32]. There is a strong peak in the region of $1,060-1,030 \mathrm{~cm}^{-1}$ that can be assigned to stretching of C-O in C-O-H group [31] although the band is shifted to $1,070 \mathrm{~cm}^{-1}$ due to interaction with unsaturated bonds [24]. The $\mathrm{CH}_{2}$ rocking band at $928 \mathrm{~cm}^{-1}$ and a peak at $848 \mathrm{~cm}^{-1}$, which are associated with $\mathrm{C}-\mathrm{O}$ stretching, are evidenced in the spectra as well [28].

The most visible difference between PVA and PVA + $\mathrm{ADD}$ is the growth of the intensity of the $\mathrm{O}-\mathrm{H}$ peaks in the spectrum of the cross-linked material. Initially, it can be considered that the peak undergoes a decrease in the intensity as a manifestation of the presence of acetal bridges which causes a lower amount of hydroxyl groups in the material [23]. Nonetheless, apart from GA, the plasticizing function of LA affects the morphology of the material and the contrary effect appears. The presence of the $\mathrm{C}=\mathrm{O}$ band at approximately $1,720 \mathrm{~cm}^{-1}$ may indicate that the aldehyde groups of GA did not completely react with $\mathrm{O}-\mathrm{H}$ groups of the PVA chain or the contribution of remaining acetate groups of the PVA structure. In addition, the $\mathrm{C}-\mathrm{O}$ stretching at $1,088 \mathrm{~cm}^{-1}$ in pure PVA is replaced by a broader absorption band located between 1,000 and $1,140 \mathrm{~cm}^{-1}$ which can be attributed to the ether $(\mathrm{C}-\mathrm{O})$ and the acetal ring $(\mathrm{C}-\mathrm{O}-\mathrm{C})$ bands formed by the cross-linking reaction of PVA with GA. It can be assumed that GA has acted as a chemical cross-linker among PVA polymer chains [33].

The spectrum of CA shows a weak and broad band at $3,562 \mathrm{~cm}^{-1}$ which corresponds to the stretching of unsubstituted $\mathrm{O}-\mathrm{H}$ group [34] followed by the presence of the stretching vibration mode of $-\mathrm{CH}$ - located at 2,956 and $2,891 \mathrm{~cm}^{-1}$ [35-37]. There is a strong adsorption band at $1,750 \mathrm{~cm}^{-1}$ related to the symmetric stretching $\mathrm{C}=\mathrm{O}$ of the acetyl group and the medium intensity band at $1,374 \mathrm{~cm}^{-1}$, connected to the angular distortion of the $\mathrm{C}-\mathrm{H}$ in the ester methyl group typical of partially acetylated cellulose [34, 38]. The bands placed at 1,239 and $1,051 \mathrm{~cm}^{-1}$ correspond to the asymmetric vibration of $\mathrm{C}-\mathrm{O}-\mathrm{C}$ for ether bridge and pyranose ring, respectively [35]. The presence of PEG in the spectrum is manifested only as an outstanding increase of the signal for $\mathrm{OH}$ groups and $\mathrm{CH}$ stretching at 3,485, 2,947, and $2,864 \mathrm{~cm}^{-1}$.

The spectrum for each side of the BAPM evidences a high degree of correspondence between the single layers which can be considered as indicator that the surfaces keep their morphology after the formation of the bilayers.

3.2. Contact Angle (Surface Energy). The contact angle values of deionized water $\left(\theta_{\mathrm{w}}\right)$, ethylene glycol $\left(\theta_{\mathrm{e}}\right)$, and diiodomethane $\left(\theta_{\mathrm{d}}\right)$ and the corresponding evaluated surface energies are shown in Table 2. The Lifshitz-Van der Waals/acid-base (LW/AB) theory was employed to obtain the total surface energy $\Upsilon^{\text {tot }}$ and its components: dispersion $\Upsilon^{\mathrm{LW}}$ and polar $Y^{\mathrm{AB}}$. LW refers to the total dispersive Lifshitz-Van der Waals interactions and $\mathrm{AB}$ is related to the Lewis acidbase (electron acceptor/electron donor) interactions, where $\Upsilon^{+}$and $\Upsilon^{-}$are the acidic and basic parts. The method was used for evaluating both sides in each film indicated in Table 2 as air and substrate side for single components and air interface and substrate side for BAPM.

The surface energy of CA films shows that the electron acceptor components $\left(\Upsilon^{+}\right.$or Lewis acid) are very small whereas the electron donor components $\left(\Upsilon^{-}\right.$or Lewis base) are large and represent the main interactions with the electron acceptor $\Upsilon^{+}$components of the contacting liquids [39]. The number of acetyl groups increases the formed hydrogen bonding generating a wettable material which is supported by the values of contact angle as well as the total surface energy $\Upsilon^{\text {tot }}$. As a plasticizer, PEG interrupts the sequence of hydrogen bonding and the intermolecular forces are affected with the relevant rise in the basic character and $\Upsilon^{\text {tot }}$. It is not surprising that CA + ADD material exhibits the lowest contact angle values and the highest basic components or, in other words, the most wettable film [40].

PVA is a hydrophilic polymer and its hydrophilicity is caused by the hydrogen bonding occurring in the surface 
TABLE 2: Contact angle and surface energy values for the prepared materials.

\begin{tabular}{|c|c|c|c|c|c|c|c|c|}
\hline \multirow{2}{*}{ Sample } & \multicolumn{3}{|c|}{ Contact angle $\left({ }^{\circ}\right)$} & \multicolumn{5}{|c|}{ Surface energy $\left(\mathrm{mJ} / \mathrm{m}^{2}\right)$} \\
\hline & $\theta_{\mathrm{w}}$ & $\theta_{\mathrm{e}}$ & $\theta_{\mathrm{d}}$ & $\gamma^{\text {tot }}$ & $\gamma^{\mathrm{LW}}$ & $\gamma^{\mathrm{AB}}$ & $\gamma^{+}$ & $\gamma^{-}$ \\
\hline CA (air side) & $63.75 \pm 2.14$ & $38.14 \pm 4.78$ & $39.27 \pm 4.47$ & 42.14 & 39.97 & 2.17 & 0.06 & 18.48 \\
\hline CA (substrate side) & $64.12 \pm 2.89$ & $38.38 \pm 3.92$ & $43.62 \pm 4.48$ & 41.44 & 37.74 & 3.69 & 0.19 & 17.96 \\
\hline $\mathrm{CA}+\mathrm{ADD}$ (air side) & $42.03 \pm 4.47$ & $28.78 \pm 3.98$ & $30.75 \pm 2.39$ & 50.53 & 43.91 & 6.62 & 0.26 & 47.81 \\
\hline $\mathrm{CA}+\mathrm{ADD}$ (substrate side) & $39.85 \pm 7.04$ & $32.18 \pm 2.54$ & $30.83 \pm 1.45$ & 54.95 & 43.88 & 11.07 & 0.56 & 54.30 \\
\hline PVA (air side) & $54.79 \pm 11.66$ & $30.19 \pm 3.49$ & $39.36 \pm 4.63$ & 43.13 & 39.93 & 3.20 & 0.09 & 27.20 \\
\hline PVA (substrate side) & $62.81 \pm 7.19$ & $29.14 \pm 1.84$ & $38.19 \pm 3.12$ & 46.10 & 40.51 & 5.59 & 0.51 & 15.21 \\
\hline PVA + ADD (air side) & $75.55 \pm 5.58$ & $42.49 \pm 5.28$ & $44.15 \pm 3.59$ & 41.48 & 37.46 & 4.01 & 0.64 & 6.58 \\
\hline PVA + ADD (substrate side) & $74.49 \pm 2.52$ & $40.77 \pm 3.32$ & $45.40 \pm 4.48$ & 41.54 & 36.79 & 4.75 & 0.82 & 6.87 \\
\hline BAPM: PVA + ADD (air side) & $49.93 \pm 5.25$ & $28.91 \pm 2.88$ & $38.47 \pm 5.10$ & 41.77 & 40.37 & 1.40 & 0.01 & 34.27 \\
\hline BAPM: PVA + ADD (interface) & $40.75 \pm 4.27$ & $24.31 \pm 5.90$ & $35.54 \pm 5.45$ & 43.70 & 41.78 & 1.92 & 0.02 & 46.69 \\
\hline BAPM: CA + ADD (interface) & $49.21 \pm 3.37$ & $32.91 \pm 2.41$ & $34.79 \pm 5.42$ & 45.59 & 42.13 & 3.47 & 0.08 & 38.39 \\
\hline BAPM: CA + ADD (substrate side) & $46.04 \pm 3.88$ & $26.98 \pm 3.44$ & $38.81 \pm 2.47$ & 41.03 & 40.20 & 0.82 & 0.00 & 39.49 \\
\hline
\end{tabular}

between free $\mathrm{OH}$ groups and the water molecules showing a basic nature $\left(\Upsilon^{+}<\Upsilon^{-}\right)$. This nature is reduced substantially in PVA + ADD because the cross-linker agent diminishes the amount of available hydroxyl groups in the polymer matrix generating a rise of the contact angle values for the three tested liquids [41]. Moreover, the hydrophilicity is affected by the crystallinity as well, and DSC results (see below) indicated a higher value for PVA + ADD than just for PVA. Nonetheless, a slight drop in $\Upsilon^{\text {tot }}$ indicates that the wettability in this material is lower since the proportion of hydrogen bonding was reduced and because the wettability of liquid droplets on solid surfaces is governed mainly by both the chemical composition and the geometrical microstructure [42].

The measured values are slightly different depending on the surface that the polymer is in contact with (air, substrate, or interface). In the case of PVA, the variation can be attributed to the probability of the polymer chains mobility toward neighboring molecules. In the air side, the hydrophilic groups migrate to the inner bulk part due to the hydrophobic character of the air. On the contrary, in the substrate side, the polar groups migrate from the bulk to the substrate as the glass is hydrophilic material. As a result, higher values for the contact angle in the air side can be expected. However, a competition between glass (substrate) and surrounded molecules (water) is presented and PVA exhibits higher values for the substrate side. These effects were not detected for the other films and the values do not present notable differences because the repulsion to hydrophobic surface is attenuated by the presence of additives.

By analyzing $\Upsilon^{\text {tot }}$ in the BAPM, one piece of data deserves a deeper sight. The film CA + ADD (substrate side) is considerably higher in the BAPM than in the individual component whereas the other components exhibit surprising closer values. A plausible explanation for these unexpected results is correlated to the surface morphology. SEM evidenced those differences (see below). Despite the slight differences, it is possible to claim that, in the BAPM, the surfaces of the individual components retain their surface characteristics which are an important indicative of their potential use as a material in medical field.
3.3. Scanning Electron Microscopy (SEM). The SEM images provide valuable information which can confirm the results found through surface energy analysis. No differences were seen in PVA and PVA + ADD either as a single component or as a part of the BAPM in the bilayer structures. Nonetheless, a dissimilar analysis can be done for the changes in CA films. As was explained, during drying process, the polar groups tend to migrate in a different manner according to the interface which the material is in contact with. As a hydrophobic substance, there is important repulsion of the CA molecules in air generating a roughness surface whereas the substrate (glass) side looks smoother (Figures 2(a) and 2(b)).

However, the surface smoothness decreases due to the presence of PEG as can be seen in Figures 2(a) and 2(c) as well as in Figures 2(b) and 2(d). The porous formation causes these differences. The PEG boosts the formation of pores in the structure which indeed can be correlated with the results for gas permeability where CA + ADD exhibit higher values than CA (shown below). CA molecules on the other hand are immobilized in a glassy state as a consequence of the effect of acetone during the casting and the crystallinity of this film is considerably lower than the crystallinity of CA + ADD (see DSC results) [43, 44]. By comparing Figures 2(c) and 2(d), minor differences in the roughness are revealed. They are caused by the interaction of the material with the hydrophilic and hydrophobic character of the interface. Nonetheless, the analysis of Figures 2(c) and 2(e) as well as Figures 2(d) and $2(\mathrm{f})$ indicates that the most notable difference is the appearance of a needle-shaped structure on the interfaces of the bilayers. The surfaces of the interfaces look smoother than the single component in contact with the same media, probably due to the interaction of the plasticizer with water and PVA molecules. Moreover, the aqueous solution of PVA induces the formation of crystals on the surface, and it causes a reduction on the pores formation (the surface of the material in Figure 2(e) appears smoother than in Figure 2(f)).

3.4. Differential Scanning Calorimetry (DSC). A representative DSC thermogram of the second scan for CA films is shown in Figure 3(a). The melting temperature $\left(T_{m}\right)$ is 


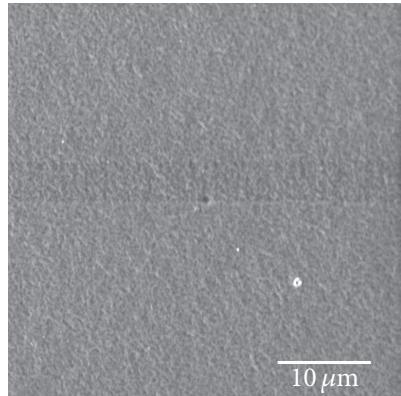

(a)

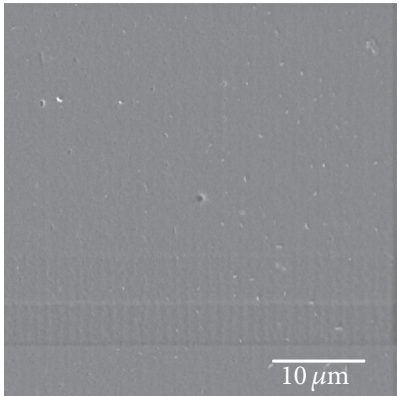

(b)

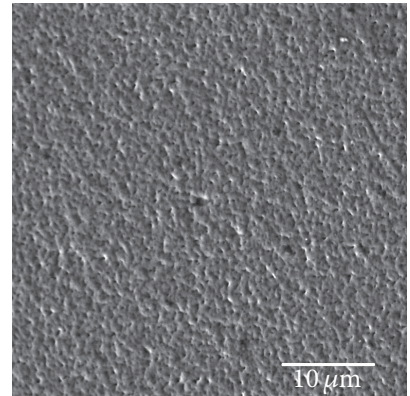

(c)

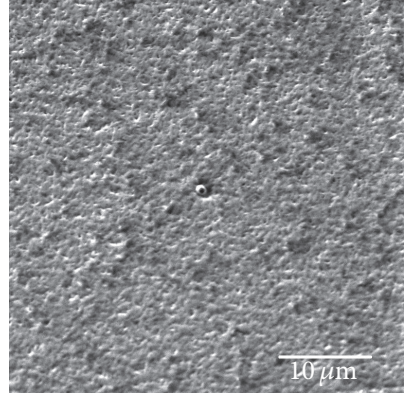

(d)

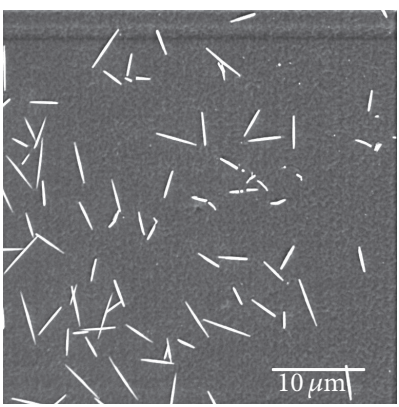

(e)

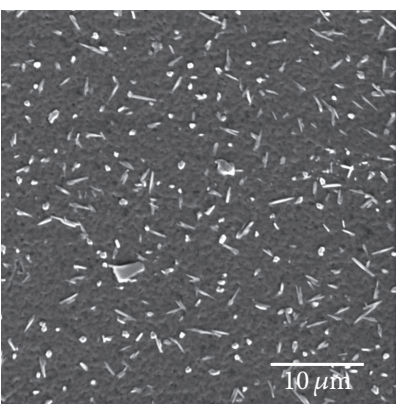

(f)
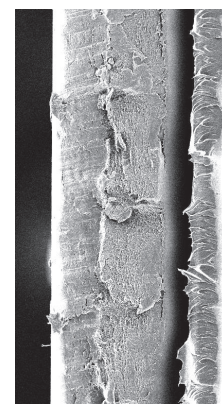

$(\mathrm{g})$

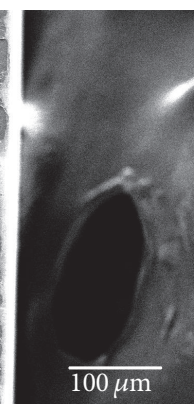

FIGURE 2: SEM images for the surface of the prepared materials. (a) CA air side; (b) CA substrate side; (c) CA + ADD air side; (d) CA + ADD substrate side; (e) bilayer: CA + ADD interface; (f) bilayer: CA + ADD substrate side; and (g) cross section of the BAPM (bilayer structure).

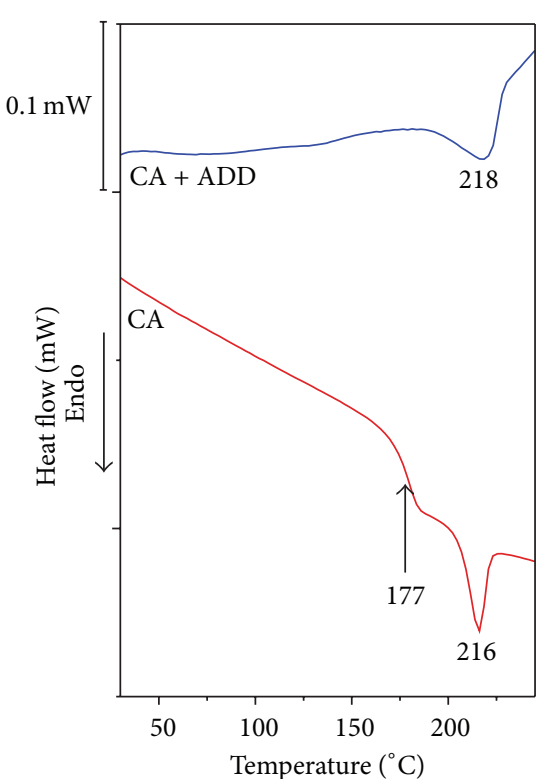

(a)

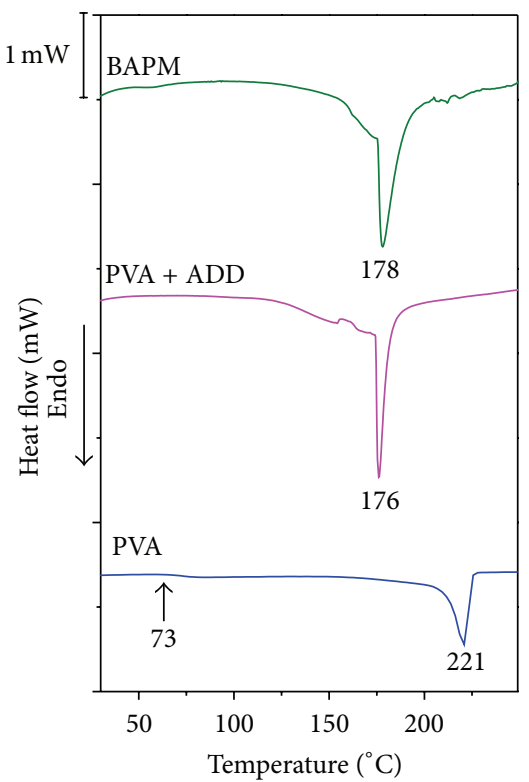

(b)

FIGURE 3: DSC thermograms for (a) CA systems and (b) PVA systems.

centered at $216^{\circ} \mathrm{C}$ whereas the glass transition temperature $\left(T_{g}\right)$ is located at $177^{\circ} \mathrm{C}$, transitions which have been reported somewhere else [45-47]. Nevertheless, CA with different degrees of acetylation shows $T_{g}$ values between 190 and $220^{\circ} \mathrm{C}[48,49]$ and a higher DS causes a lower possibility of forming hydrogen bonding and consequently a lower $T_{g}$ is manifested [50]. In addition, detecting those transitions is difficult since the heat capacity change of polymers at $T_{g}$ is related to the increase in molecular mobility which is not very large in rigid cellulose acetate [51]. The proximity of $T_{g}$ and $T_{m}$ interferes with the crystallization process that occurs between them. CA revealed that only the mixed esters, in 
TABLE 3: Permeability coefficient in Barrer for the studied material.

\begin{tabular}{|c|c|c|c|c|}
\hline Film & Air & Nitrogen $\left(\mathrm{N}_{2}\right)$ & Oxygen $\left(\mathrm{O}_{2}\right)$ & Carbon dioxide $\left(\mathrm{CO}_{2}\right)$ \\
\hline $\mathrm{CA}$ & 0.1142 & 0.3201 & 0.5321 & 0.5910 \\
\hline $\mathrm{CA}+\mathrm{ADD}$ & 0.2205 & 0.5360 & 0.5619 & 0.5946 \\
\hline PVA & 0.0067 & 0.0073 & 0.0106 & 0.0852 \\
\hline $\mathrm{PVA}+\mathrm{ADD}$ & 0.0033 & 0.0040 & 0.0090 & 0.0528 \\
\hline Bilayer (CA + ADD down*) & 0.4061 & 0.4445 & 0.7709 & 4.0960 \\
\hline Bilayer (PVA + ADD down $\left.{ }^{*}\right)$ & 0.3947 & 0.4070 & 0.7196 & 2.3140 \\
\hline
\end{tabular}

${ }^{*}$ In contact with the lower chamber or chamber with the lower pressure.

which the bulkier acyl group is in the range of DS 0.3-1.0, have a $\Delta\left(T_{m}-T_{g}\right)$ value in excess of $40^{\circ} \mathrm{C}$ [52]. The thermal behavior of $\mathrm{CA}$ is also influenced by the regiochemistry and the method of preparation [53]. The addition of low molecular weight plasticizer results in the decrease of the intermolecular forces between the polymer chains due to shielding of functional (polar) groups along the polymer chains. That leads to an increase in free volume and chain mobility. As a result, $T_{g}$ of CA $+\mathrm{ADD}$ should be lower than the value for CA. Furthermore, it has been reported that $T_{g}$ for CA plasticized with PEG is reduced depending on the concentration of the plasticizer [54]. However, it was not detected as was explained previously [55] and because, in a conventional DSC, a reversing event like the glass transition may be hidden by a no reversing event, such as enthalpic relaxation [50].

In Figure 3(b), the thermal transitions for the second scan of PVA are shown. Two main events appeared: $T_{m}$ which is located at $221^{\circ} \mathrm{C}$ and $T_{g}$ at $73^{\circ} \mathrm{C}$. Although several sources report that $T_{g}$ can be found at $85^{\circ} \mathrm{C}$ [56-62], it is well known that the presence of water could act as a plasticizer causing a reduction in this value [63]. The effects caused by ADD were analyzed in a previous study [60]. Nonetheless, it can be mentioned that PVA $+\mathrm{ADD}$ exhibits a lower $T_{m}$ than pure PVA. The addition of the ADD shows that plasticizing effect of LA predominated in the system because it has the highest concentration in the system (15\% in comparison with $0.25 \%$ of GA) and because LA is partially grafted on hydroxyl groups of PVA which, generally, causes disturbing or attenuation of hydrogen bonding between parallel PVA chains as well as disturbing of regularity of chain stacking by the presence of randomly distributed lactide groups pendant to polymer chains [19].

The first scan for BAPM is exhibited in Figure 3(b). As can be observed, CA + ADD transitions are hidden by the PVA + ADD one. Nonetheless, it is worth mentioning that both individual polymers do not interact beyond the interface because the polymers interactions are evidenced by this technique as a unique $T_{g}$. If any sample of a binary polymer system exhibits a single glass transition between the $T_{g}$ values of both components and a composition-dependent shift in $T_{g}$ of the blend is clearly observed, then the system can be regarded as a highly miscible one. In the case where one component is crystalline, observation of a melting point depression of this polymer also supports the miscibility of the polymer pair [64]. However, it is not the present case, which confirms that CA + ADD and PVA + ADD keep their structural, functional, and morphological integrity in the BAPM.

3.5. Gas Permeability. The permeability coefficient is the volume of gas which, under steady conditions, crosses unit area and unit thickness of the sample in unit time under unit pressure difference and at constant temperature.

Table 3 shows the permeability coefficient in Barrer $\left(10^{-10} \mathrm{~cm}^{3}\right.$ (STP) $\left.\mathrm{cm} / \mathrm{cm}^{2} \mathrm{~s} \mathrm{~cm} \mathrm{Hg}\right)$ for the tested samples. Gas transmission process includes three phases. In the first one, the molecules in the room with higher pressure are condensed on the surface of the film. Next, the gas is dissolved into the film and finally it leaves the polymer and experiments desorb.

The four gases permeate in a greater extent $(\mathrm{CA}+\mathrm{ADD})$ than just $\mathrm{CA}$ and the reason can be found in the higher porosity that exhibits the $\mathrm{CA}+\mathrm{ADD}$ as a consequence of the structural changes that are caused by PEG which is a hydrophilic plasticizer and a pore former [65]. Manifestations of those changes were corroborated by SEM (see above) in which CA + ADD film seems to exhibit a more roughness surface in comparison with CA. In addition to the structural modifications, PEG reduces slightly the crystallinity of the natural polymer (see DSC results). Therefore, the permeability is increased because the crystalline zones act as excluded volumes for the sorption process and are impermeable barriers for the diffusion. Two more effects on the gas diffusion are owing to the crystalline regions. The increase in the effective path length of diffusion and the reduction of the mobility in the amorphous phase (because chain ends are trapped in the neighboring crystalline lamellae) cause a higher activation energy of diffusion [66].

PVA is a good gas barrier polymer and this behavior is a consequence of the large inter- and intramolecular cohesive energy that results from the highly polar alcohol $(-\mathrm{OH})$ functionality with the low polarity gases [67] combined with the presence of crystalline regions in the matrix. It is well worth bringing the attention to the fact that PVA $+\mathrm{ADD}$ is even less permeable than PVA. By reducing those interactions in presence of ADD, lesser amounts of available hydroxyl groups are present in the matrix; therefore a reduction in the interaction points is achieved and decreases in permeability are presented because the polymer cohesions are weakened. Moreover, the higher crystallinity of PVA + ADD in comparison with PVA (evidenced in DSC) reduces 
TABLE 4: Water vapor transmission and water vapor permeability for the prepared materials.

\begin{tabular}{lcr}
\hline Sample & WVT $\left(\mathrm{kg} / \mathrm{s} \cdot \mathrm{m}^{2}\right)$ & $\mathrm{WVP}\left(\mathrm{kg} \cdot \mathrm{m} / \mathrm{s} \cdot \mathrm{m}^{2} \cdot \mathrm{kPa}\right)$ \\
\hline CA & $9.6694 \times 10^{-07} \pm 3.7695 \times 10^{-08}$ & $9.5310 \times 10^{-11} \pm 6.1328 \times 10^{-12}$ \\
CA + ADD & $2.2465 \times 10^{-06} \pm 2.1142 \times 10^{-07}$ & $1.9991 \times 10^{-10} \pm 5.9032 \times 10^{-11}$ \\
PVA & $4.9046 \times 10^{-09} \pm 8.4208 \times 10^{-10}$ & $3.3116 \times 10^{-13} \pm 1.1558 \times 10^{-13}$ \\
PVA + ADD & $4.8077 \times 10^{-08} \pm 4.2441 \times 10^{-09}$ & $4.7179 \times 10^{-12} \pm 7.6930 \times 10^{-13}$ \\
Bilayer CA side waxed & $7.5240 \times 10^{-08} \pm 1.1491 \times 10^{-08}$ & $2.6514 \times 10^{-11} \pm 5.4760 \times 10^{-12}$ \\
Bilayer PVA side waxed & $4.2572 \times 10^{-07} \pm 2.8003 \times 10^{-08}$ & $8.0962 \times 10^{-11} \pm 1.0785 \times 10^{-11}$ \\
\hline
\end{tabular}

the gas solubility and a more tortuous path for the diffusing species occurs [68].

Air displays the lowest permeation to the films. On the contrary, $\mathrm{CO}_{2}$ flaunts the highest permeability for every single material because of its small kinetic diameter, its high condensability, and more interaction of this gas with polar groups in polymer compared to $\mathrm{O}_{2}$ and $\mathrm{N}_{2}$ [69-71]; meanwhile oxygen gas values were greater than those of nitrogen, regardless of types of film. This is mainly due to the difference in the size of the gases.

A different issue appears for the bilayer. As a first step, the bilayer system consists of two monolayers that exhibit different permeabilities and thicknesses. However, the used apparatus considers the material as a unique film and for that reason the permeability coefficient is calculated using the thickness of the bilayer, provoking a variation in the final result. The theories developed in order to understand how a bilayer is permeated are still in constant evolution and there is no end point in this topic. However, the steady-state barrier properties of multilayer films are a valuable tool which explains partially this phenomenon by treating the individual layers as resistances in series as is shown in

$$
\frac{1}{P^{\prime}}=\frac{L t}{P t}=\frac{L 1}{P 1}+\frac{L 2}{P 2}+\cdots+\frac{L n}{P n},
$$

where $P t, L t$, and $P$ are permeability, thickness, and permeance of the composite structure, and $P 1, P 2, \ldots, P n$ and $L 1, L 2, \ldots, L n$ are the permeabilities and thicknesses of the individual layers [72]. A second consideration has to be taken into account. When the pressure on the upstream side of the membrane is increased, two opposite effects may occur: a hydrostatic pressure increase leads to an increase of the polymer density, via polymer compaction, thereby reducing the free volume inside the polymer; the pressure increase corresponds to an increase of the penetrant concentration in the membrane. These diffusing molecules plasticize the macromolecular chains. The first one of these two mechanisms tends to retard the diffusion process by reducing the segmental motions whereas the second enhances it [66]. Furthermore, the diffusion process has been explained whether by obeying or not the Fick diffusion law. In the first case, the mobility of the penetrant is slower than the polymer chain mobility and the rate of penetrant mass uptake is proportional to the square root of time. In the second case, the rate of mass uptake is directly proportional to time. Penetrant diffusion rate is faster than the chain mobility, thereby leading to swelling of the polymer. Anomalous sorption occurs during comparable mobility of both the penetrant and the polymer chain. Due to the complex nature of the sorption kinetics, this behavior is termed either anomalous or non-Fickian [73]. By combining all the aforementioned reasons, the permeation in the bilayers is unusually high in comparison with the monolayers.

3.6. Water Permeability. Table 4 presents the water vapor transmission (WVT) and water vapor permeability (WVP) results for the prepared materials. As can be noticed, PVA presents the lowest values of these two parameters which might be caused by the hydrophilic behavior of the synthetic polymer. In fact, it absorbs water vapor and provokes a decrease on the WVT of the films by comparing with the other films [74]. On the other hand, PVA + ADD film shows higher values than just PVA. It is well known that increasing the hydrophilic nature of a polymer membrane induces water vapor tendency and as a result increases water vapor permeation $[75,76]$. Into the bargain, it might be thought that GA can decrease WVT because the water vapor transfer process across the films depends on the degree of cross-linking and PVA chains covalently cross-linked to each other block the pathway of water and restrict the water vapor penetration across the films [74]. Nonetheless, PVA + ADD is less hydrophilic than PVA (see contact angle results) although it is more porous (confirmed by SEM) and the plasticizing effect caused by LA generates a rise in the free volume. The combination of these factors produces a material with a higher WVT. By contrast, CA and CA + ADD films are the least permeable to water. $\mathrm{CA}$ is the second most hydrophobic material in this study which can be interpreted as a signal of its low WVT character. Notwithstanding, PEG as a hydrophilic additive changes the membrane morphology forming micropores in the film structures due to the microphase separation process. As a result, the pure water permeation is increased $[77,78] 2.3$ times approximately. The water absorption capacity is boosted by an improvement in the surface free energy [75] and these results are supported by the contact angle results and vice versa. Finally, although it can be expected that the material with the lowest WVT dominates the permeability in the BAPM, it has to be mentioned that the thicknesses of the layers which conform the BAPM are not the same; therefore the obtained values are different and they are located in between the WVP of CA + ADD and PVA + ADD.

3.7. Mechanical Properties. Young's modulus $(E)$, stress at break $(\sigma)$, and elongation at break $(\varepsilon)$ were chosen for 
TABLE 5: Mechanical properties for the prepared material.

\begin{tabular}{lcccc}
\hline Sample & Young's modulus $(\mathrm{MPa})$ & Tensile strength $(\mathrm{MPa})$ & Elongation at break $(\%)$ & Thickness $(\mathrm{mm})$ \\
\hline CA & $1,832 \pm 71$ & $38 \pm 4$ & $7 \pm 3$ & $0.253 \pm 0.01$ \\
CA + ADD & $660 \pm 87$ & $13 \pm 2$ & $10 \pm 2$ & $0.311 \pm 0.03$ \\
PVA & $1,174 \pm 189$ & $16 \pm 6$ & $69 \pm 15$ & $0.128 \pm 0.04$ \\
PVA + ADD & $49 \pm 6$ & $18 \pm 3$ & $217 \pm 25$ & $0.094 \pm 0.01$ \\
Bilayer & $590 \pm 53$ & $11 \pm 3$ & $13 \pm 4$ & $0.340 \pm 0.02$ \\
\hline
\end{tabular}

evaluating the prepared material as well as the influence of the ADD in the single components. Table 5 shows the obtained results. CA is a brittle polymer which exhibits notably high Young's modulus and a small elongation at break. No yield point was manifested during the measurements, confirming the brittleness of the material $[50,64]$. Plasticization, on the contrary, is assumed to increase the flexibility of chains and lead to a decrease in stiffness [79]. The presence of PEG produces polymer-plasticizer interactions among the macromolecules to the detriment of polymer-polymer interactions and it causes a decrease of the hardness as well as Young's modulus whereas the elongation at break was increased. In case of PVA, the stress-strain curve is affected by molecular weight, crystallinity, type, and proportion of additives. The elongation at break for PVA + ADD in comparison with PVA was significantly higher as a consequence of the plasticizing effect caused by LA [80]. Furthermore, the low elongation at break for the bilayer is a result of the poorer mechanical features of $\mathrm{CA}+\mathrm{ADD}$. As a remarkable point, in the BAPM systems, during the test CA + ADD failed always at first, and it demonstrates that in the BAPM the mechanical properties are governed by the natural polymer as the weakest material in the bilayer.

\section{Conclusions}

The primary aim of this research was to obtain and characterize a new bioartificial polymeric material prepared from CA and PVA. Casting method, as a simple polymer production technique, was used for that purpose and a bilayer with two separated and well-differentiated surfaces was successfully obtained. The characterization techniques have provided relevant and sufficient data which allows claiming that the achieved material fulfills one of the basic requirements for BAPM: to enhance the mechanical characteristics of biopolymers. FTIR, contact angle, and SEM have indicated that the BAPM exhibits two independent surfaces which are closely related to the polymers that compose the bilayer. On the other hand, DSC did not indicate any evidence of the formation of a blend or an interpenetrating structure in the interface by the exhibition of just one $T_{g}$. A substantial reduction in the brittleness of the natural polymer was achieved by adding PEG meanwhile Young's modulus was three times smaller and a slight but relevant rise in elongation was achieved. PVA was modified using LA, GA, and $\mathrm{H}^{+}$, thus accomplishing a material with a stunning reduction in Young's modulus and a significant improvement in elongation at break. The mechanical properties of BAPM are closer to CA + ADD than to PVA + ADD; therefore, it could be argued that the natural polymer dominates the behavior of the bioartificial polymeric material.

The improvement in the permeability is crucial considering the potential use of the material in the medical field, since gases or nutrients can penetrate in a higher proportion into the film and, as a consequence, into the possible biological scaffold including exudation as a relevant part of the healing and regeneration. For all of the given reasons, the BAPM can be considered as a promising candidate that should undergo further analysis in order to determine its applicability in medicine field.

\section{Competing Interests}

The authors declare that they have no competing interests.

\section{Acknowledgments}

This work was supported by the Ministry of Education, Youth and Sports of the Czech Republic-Program NPU I (LO1504).

\section{References}

[1] M. G. Cascone, "Dynamic-mechanical properties of bioartificial polymeric materials," Polymer International, vol. 43, no. 1, pp. 55-69, 1997.

[2] H.-M. Wang, Y.-T. Chou, C.-S. Wu, and J.-T. Yeh, "Polyester/ cellulose acetate composites: preparation, characterization and biocompatible," Journal of Applied Polymer Science, vol. 126, no. 2, pp. E242-E251, 2012.

[3] T. Ohno, S. Yoshizawa, Y. Miyashita, and Y. Nishio, "Interaction and scale of mixing in cellulose acetate/poly $(N$-vinyl pyrrolidone-co-vinyl acetate) blends," Cellulose, vol. 12 , no. 3 , pp. 281-291, 2005.

[4] R. Konwarh, N. Karak, and M. Misra, "Electrospun cellulose acetate nanofibers: the present status and gamut of biotechnological applications," Biotechnology Advances, vol. 31, no. 4, pp. 421-437, 2013.

[5] X. Liu, T. Lin, Y. Gao et al., "Antimicrobial electrospun nanofibers of cellulose acetate and polyester urethane composite for wound dressing," Journal of Biomedical Materials Research Part B: Applied Biomaterials, vol. 100, no. 6, pp. 1556-1565, 2012.

[6] B. Ding, H.-Y. Kim, S.-C. Lee et al., "Preparation and characterization of a nanoscale poly(vinyl alcohol) fiber aggregate produced by an electrospinning method," Journal of Polymer Science, Part B: Polymer Physics, vol. 40, no. 13, pp. 1261-1268, 2002. 
[7] H. Kaczmarek and A. Podgórski, "The effect of UV-irradiation on poly(vinyl alcohol) composites with montmorillonite," Journal of Photochemistry and Photobiology A: Chemistry, vol. 191, no. 2-3, pp. 209-215, 2007.

[8] P. Alexy, D. Bakoš, S. Hanzelová et al., "Poly(vinyl alcohol)collagen hydrolysate thermoplastic blends: I. Experimental design optimisation and biodegradation behaviour," Polymer Testing, vol. 22, no. 7, pp. 801-809, 2003.

[9] L. W. Chan, J. S. Hao, and P. W. S. Heng, "Evaluation of permeability and mechanical properties of composite polyvinyl alcohol films," Chemical and Pharmaceutical Bulletin, vol. 47, no. 10, pp. 1412-1416, 1999.

[10] N. A. El-Zaher and W. G. Osiris, "Thermal and structural properties of poly(vinyl alcohol) doped with hydroxypropyl cellulose," Journal of Applied Polymer Science, vol. 96, no. 5, pp. 1914-1923, 2005.

[11] Y. Jiang, A. Schädlich, E. Amado et al., "In-vivo studies on intraperitoneally administrated poly(vinyl alcohol)," Journal of Biomedical Materials Research Part B: Applied Biomaterials, vol. 93, no. 1, pp. 275-284, 2010.

[12] W. Y. Zhou, B. Guo, M. Liu, R. Liao, A. B. M. Rabie, and D. Jia, "Poly(vinyl alcohol)/Halloysite nanotubes bionanocomposite films: properties and in vitro osteoblasts and fibroblasts response," Journal of Biomedical Materials Research-Part A, vol. 93, no. 4, pp. 1574-1587, 2010.

[13] J.-S. Park, J.-W. Park, and E. Ruckenstein, "A dynamic mechanical and thermal analysis of unplasticized and plasticized poly(vinyl alcohol)/methylcellulose blends," Journal of Applied Polymer Science, vol. 80, no. 10, pp. 1825-1834, 2001.

[14] S. I. Ahmad, N. Hasan, C. K. V. Z. Abid, and N. Mazumdar, "Preparation and characterization of films based on crosslinked blends of gum acacia, polyvinylalcohol, and polyvinylpyrrolidone-iodine complex," Journal of Applied Polymer Science, vol. 109, no. 2, pp. 775-781, 2008.

[15] C. A. Scotchford, M. G. Cascone, S. Downes, and P. Giusti, "Osteoblast responses to collagen-PVA bioartificial polymers in vitro: the effects of cross-linking method and collagen content," Biomaterials, vol. 19, no. 1-3, pp. 1-11, 1998.

[16] A. Bernal, R. Balkova, I. Kuritka, and P. Saha, "Preparation and characterisation of a new double-sided bio-artificial material prepared by casting of poly(vinyl alcohol) on collagen," Polymer Bulletin, vol. 70, no. 2, pp. 431-453, 2013.

[17] J. Yuan, P. P. Shang, and S. H. Wu, "Effects of polyethylene glycol on morphology, thermomechanical properties, and water vapor permeability of cellulose acetate-free films," Pharmaceutical Technology, vol. 25, no. 10, pp. 62-74, 2001.

[18] ISO, "Plastics-determination of tensile properties-part 3: test conditions for films and sheets," ISO 527-3:1995, 1995.

[19] ISO, "Plastics — standard atmospheres for conditioning and testing," ISO 291:1997, 1997.

[20] A. Bernal, I. Kuritka, V. Kasparkova, and P. Saha, "The effect of microwave irradiation on poly(vinyl alcohol) dissolved in ethylene glycol," Journal of Applied Polymer Science, vol. 128, no. 1, pp. 175-180, 2013.

[21] C. Finch, Polyvinyl Alcohol Developments, John Wiley \& Sons, Chichester, UK, 1992.

[22] B. J. Holland and J. N. Hay, "The thermal degradation of poly(vinyl alcohol)," Polymer, vol. 42, no. 16, pp. 6775-6783, 2001.

[23] H. S. Mansur, C. M. Sadahira, A. N. Souza, and A. A. P. Mansur, "FTIR spectroscopy characterization of poly (vinyl alcohol) hydrogel with different hydrolysis degree and chemically crosslinked with glutaraldehyde," Materials Science and Engineering C, vol. 28, no. 4, pp. 539-548, 2008.

[24] J. Lambert, H. Shurvell, D. Lighner, and R. Graham, Organic Structural Spectroscopy, Prentice Hall, New York, NY, USA, 2001.

[25] J. Dabrowski and M. Tencer, "Rotational Isomerism in $\beta$ Diketone cis and trans Enol Ethers. An IR and PMR Study," Bulletin of the Chemical Society of Japan, vol. 49, no. 4, pp. 981986, 1976.

[26] E. Y. Gren, A. K. Grinvalde, and G. Y. Vanag, "Infrared spectra and enolization of simple 1, 3-diketones," Journal of Applied Spectroscopy, vol. 6, no. 2, pp. 146-150, 1970.

[27] S. F. Tayyari, M. Zahedi-Tabrizi, S. Laleh, Z. Moosavi-Tekyeh, H. Rahemi, and Y. A. Wang, "Structure and vibrational assignment of 3,4-diacetyl-2,5-hexanedione. A density functional theoretical study," Journal of Molecular Structure, vol. 827, no. 1-3, pp. 176-187, 2007.

[28] N. V. Bhat, M. M. Nate, M. B. Kurup, V. A. Bambole, and S. Sabharwal, "Effect of $\gamma$-radiation on the structure and morphology of polyvinyl alcohol films," Nuclear Instruments and Methods in Physics Research, Section B: Beam Interactions with Materials and Atoms, vol. 237, no. 3-4, pp. 585-592, 2005.

[29] S.-S. Wong, S. A. Altinkaya, and S. K. Mallapragada, "Crystallization of poly(vinyl alcohol) during solvent removal: infrared characterization and mathematical modeling," Journal of Polymer Science Part B: Polymer Physics, vol. 45, no. 8, pp. 930-935, 2007.

[30] N. V. Alekseeva, A. M. Evtushenko, I. P. Chikhacheva, V. P. Zubov, and I. V. Kubrakova, "Effect of microwave irradiation on the structuring of polyvinyl alcohol," Mendeleev Communications, no. 4, pp. 170-172, 2005.

[31] N. V. Petrova, A. M. Evtushenko, I. P. Chikhacheva, V. P. Zubov, and I. V. Kubrakova, "Effect of microwave irradiation on the cross-linking of polyvinyl alcohol," Russian Journal of Applied Chemistry, vol. 78, no. 7, pp. 1158-1161, 2005.

[32] G. N. Hemantha, J. Lakshmana, N. Gopal, K. Narasimhulu, R. Chakradhar, and A. Varada Rajulu, "Spectroscopic investigations of $\mathrm{Mn}^{2+}$ ions doped polyvinylalcohol films," Polymer, vol. 45, no. 16, pp. 5407-5415, 2004.

[33] G. Andrade, E. F. Barbosa-Stancioli, A. A. Piscitelli Mansur, W. L. Vasconcelos, and H. S. Mansur, "Design of novel hybrid organic-inorganic nanostructured biomaterials for immunoassay applications," Biomedical Materials, vol. 1, no. 4, pp. 221-234, 2006.

[34] A. Aluigi, C. Vineis, A. Ceria, and C. Tonin, "Composite biomaterials from fibre wastes: Characterization of wool-cellulose acetate blends," Composites Part A: Applied Science and Manufacturing, vol. 39, no. 1, pp. 126-132, 2008.

[35] L. M. Ilharco and R. Brito De Barros, "Aggregation of pseudoisocyanine iodide in cellulose acetate films: structural characterization by FTIR," Langmuir, vol. 16, no. 24, pp. 9331-9337, 2000.

[36] L. M. Ilharco, A. R. Garcia, J. Lopes Da Silva, and L. F. Vieira Ferreira, "Infrared approach to the study of adsorption on cellulose: influence of cellulose crystallinity on the adsorption of benzophenone," Langmuir, vol. 13, no. 15, pp. 4126-4132, 1997.

[37] T. Kondo and C. Sawatari, "A Fourier transform infra-red spectroscopic analysis of the character of hydrogen bonds in amorphous cellulose," Polymer, vol. 37, no. 3, pp. 393-399, 1996. 
[38] W. Zhou, J. He, S. Cui, and W. Gao, "Studies of electrospun cellulose acetate nanofibrous membranes," The Open Materials Science Journal, vol. 5, pp. 51-55, 2011.

[39] H. Y. Erbil, "Calculation of spreading pressure of water on cellulosic films from contact angle data," Turkish Journal of Chemistry, vol. 21, no. 4, pp. 332-345, 1997.

[40] I. Guezguez, B. Mrabet, and E. Ferjani, "XPS and contact angle characterization of surface modified cellulose acetate membranes by mixtures of PMHS/PDMS," Desalination, vol. 313, pp. 208-211, 2013.

[41] B. Bahrami, S. Kordestani, H. Mirzadeh, and P. Mansoori, "Blending of PVA and chitosan improves bulk and surface hydrophilicity of blended films," Iranian Polymer Journal, vol. 12, no. 2, pp. 139-146, 2003.

[42] S. Wu, X. Qin, and M. Li, "The structure and properties of cellulose acetate materials: a comparative study on electrospun membranes and casted films," Journal of Industrial Textiles, vol. 44, no. 1, pp. 85-98, 2014.

[43] L. Liu, G. Khang, J. M. Rhee, and H. B. Lee, "Preparation and characterization of cellulose acetate membrane for monolithic osmotic tablet," Korea Polymer Journal, vol. 7, no. 5, pp. 289-296, 1999.

[44] A. Muhammed, E. Hashash, Mekewi, Guirguis, Ramadan, and Hassanien, "Polyvinyl alcohol-cellulose acetate composite reverses osmosis membranes: I. Synthesis and characterization," Hydrology Current Research, vol. 3, article 131, 2012.

[45] G. R. Filho, R. C. da Silva, C. da Silva Meireles, R. M. N. de Assunção, and H. Otaguro, "Water flux through blends from waste materials: cellulose acetate (from sugar cane bagasse) with polystyrene (from plastic cups)," Journal of Applied Polymer Science, vol. 96, no. 2, pp. 516-522, 2005.

[46] G. Rodrigues Filho, L. C. Toledo, D. A. Cerqueira et al., "Water flux, DSC, and cytotoxicity characterization of membranes of cellulose acetate produced from sugar cane bagasse, using PEG 600," Polymer Bulletin, vol. 59, no. 1, pp. 73-81, 2007.

[47] Y. Nakai, H. Yoshimizu, and Y. Tsujita, "Enhanced gas permeability of cellulose acetate membranes under microwave irradiation," Journal of Membrane Science, vol. 256, no. 1-2, pp. 72-77, 2005.

[48] C. Chia-Wen, Effect of molecular structure on the viscoelastic properties of cellulose acetate in a ternary system [M.S. thesis], The University of British Columbia, Vancouver, Canada, 2010.

[49] D. Aoki, Y. Teramoto, and Y. Nishio, "Cellulose acetate/poly (methyl methacrylate) interpenetrating networks: synthesis and estimation of thermal and mechanical properties," Cellulose, vol. 18, no. 6, pp. 1441-1454, 2011.

[50] Y. Cao, J. Wu, T. Meng et al., "Acetone-soluble cellulose acetates prepared by one-step homogeneous acetylation of cornhusk cellulose in an ionic liquid 1-allyl-3-methylimidazolium chloride (AmimCl)," Carbohydrate Polymers, vol. 69, no. 4, pp. 665-672, 2007.

[51] G. Számel, S. Klébert, I. Sajó, and B. Pukánszky, “Thermal analysis of cellulose acetate modified with caprolactone," Journal of Thermal Analysis and Calorimetry, vol. 91, no. 3, pp. 715-722, 2008.

[52] W. G. Glasser, G. Samaranayake, M. Dumay, and V. Davé, "Novel cellulose derivatives. III. Thermal analysis of mixed esters with butyric and hexanoic acid," Journal of Polymer Science Part B: Polymer Physics, vol. 33, no. 14, pp. 2045-2054, 1995.

[53] T. Iwata, A. Fukushima, K. Okamura, and J.-I. Azuma, "DSC study on regioselectively substituted cellulose heteroesters,"
Journal of Applied Polymer Science, vol. 65, no. 8, pp. 1511-1515, 1997.

[54] F.-J. Wang, Y.-Y. Yang, X.-Z. Zhang, X. Zhu, T.-S. Chung, and S. Moochhala, "Cellulose acetate membranes for transdermal delivery of scopolamine base," Materials Science and Engineering C, vol. 20, no. 1-2, pp. 93-100, 2002.

[55] S. Zepnik, S. Kabasci, R. Kopitzky, H.-J. Radusch, and T. Wodke, "Extensional flow properties of externally plasticized cellulose acetate: influence of plasticizer content," Polymers, vol. 5, no. 3, pp. 873-889, 2013.

[56] M. S. Boroglu, S. Cavus, I. Boza, and A. Ata, "Synthesis and characterization of poly(vinyl alcohol) proton exchange membranes modified with 4,4-diaminodiphenylether-2,2-disulfonic acid," Express Polymer Letters, vol. 5, no. 5, pp. 470-478, 2011.

[57] Z. Peng and L. X. Kong, "A thermal degradation mechanism of polyvinyl alcohol/silica nanocomposites," Polymer Degradation and Stability, vol. 92, no. 6, pp. 1061-1071, 2007.

[58] O. Guirguis and M. Moselhey, "Thermal and structural studies of poly(vinyl alcohol) and hydroxypropyl cellulose blends," Natural Science, vol. 4, no. 1, pp. 57-67, 2012.

[59] S. R. Sudhamani, M. S. Prasad, and K. Udaya, "DSC and FTIR studies on Gellan and polyvinyl alcohol (PVA) blend films," Food Hydrocolloids, vol. 17, no. 3, pp. 245-250, 2003.

[60] A. Bernal, I. Kuritka, and P. Saha, "Preparation and characterization of poly(vinyl alcohol)-poly(vinyl pyrrolidone) blend: a biomaterial with latent medical applications," Journal of Applied Polymer Science, vol. 127, no. 5, pp. 3560-3568, 2013.

[61] R. F. Bhajantri, V. Ravindrachary, A. Harisha, V. Crasta, S. P. Nayak, and B. Poojary, "Microstructural studies on $\mathrm{BaCl}_{2}$ doped poly(vinyl alcohol)," Polymer, vol. 47, no. 10, pp. 3591-3598, 2006.

[62] S. Liang, J. Yang, X. Zhang, and Y. Bai, "The thermalelectrical properties of polyvinyl alcohol $/ \mathrm{AgNO}_{3}$ films," Journal of Applied Polymer Science, vol. 122, no. 2, pp. 813-818, 2011.

[63] B. Sarti and M. Scandola, "Viscoelastic and thermal properties of collagen/poly(vinyl alcohol) blends," Biomaterials, vol. 16, no. 10, pp. 785-792, 1995.

[64] Y. Miyashita, T. Suzuki, and Y. Nishio, "Miscibility of cellulose acetate with vinyl polymers," Cellulose, vol. 9, no. 3-4, pp. 215223, 2002.

[65] T. Mohammadi and E. Saljoughi, "Effect of production conditions on morphology and permeability of asymmetric cellulose acetate membranes," Desalination, vol. 243, no. 1-3, pp. 1-7, 2009.

[66] M. H. Klopffer and B. Flaconnèche, "Transport properties of gases in polymers: bibliographic review," Oil and Gas Science and Technology, vol. 56, no. 3, pp. 223-244, 2001.

[67] P. W. Labuschagne, W. A. Germishuizen, S. M. C. Verryn, and F. S. Moolman, "Improved oxygen barrier performance of poly(vinyl alcohol) films through hydrogen bond complex with poly(methyl vinyl ether-co-maleic acid)," European Polymer Journal, vol. 44, no. 7, pp. 2146-2152, 2008.

[68] J. C. Grunlan, A. Grigorian, C. B. Hamilton, and A. R. Mehrabi, "Effect of clay concentration on the oxygen permeability and optical properties of a modified poly(vinyl alcohol)," Journal of Applied Polymer Science, vol. 93, no. 3, pp. 1102-1109, 2004.

[69] A. Y. Houde, B. Krishnakumar, S. G. Charati, and S. A. Stern, "Permeability of dense (homogeneous) cellulose acetate membranes to methane, carbon dioxide, and their mixtures at elevated pressures," Journal of Applied Polymer Science, vol. 62, no. 13, pp. 2181-2192, 1996. 
[70] M. A. Semsarzadeh and B. Ghalei, "Preparation, Characterization and gas permeation properties of polyurethanesilica/polyvinyl alcohol mixed matrix membranes," Journal of Membrane Science, vol. 432, pp. 115-125, 2013.

[71] S. Hassanajili, E. Masoudi, G. Karimi, and M. Khademi, "Mixed matrix membranes based on polyetherurethane and polyesterurethane containing silica nanoparticles for separation of $\mathrm{CO}_{2} / \mathrm{CH}_{4}$ gases," Separation and Purification Technology, vol. 116, pp. 1-12, 2013.

[72] S. N. Dhoot, B. D. Freeman, and M. E. Stewart, "Barrier polymers," in Encyclopedia of Polymer Science and Technology, John Wiley \& Sons, New York, NY, USA, 2002.

[73] E. Suloff, Sorption behavior of an aliphatic series of aldehydes in the presence of poly(ethylene terephthalate) blends containing aldehyde scavenging agents [Doctoral thesis], Virginia Polytechnic Institute and State University, Blacksburg, Va, USA, 2002.

[74] S. M. M. Dadfar, G. Kavoosi, and S. M. A. Dadfar, "Investigation of mechanical properties, antibacterial features, and water vapor permeability of polyvinyl alcohol thin films reinforced by glutaraldehyde and multiwalled carbon nanotube," Polymer Composites, vol. 35, no. 9, pp. 1736-1743, 2014.

[75] A. Asadinezhad, I. Novák, M. Lehocký et al., "Polysaccharides coatings on medical-grade PVC: a probe into surface characteristics and the extent of bacterial adhesion," Molecules, vol. 15, no. 2, pp. 1007-1027, 2010.

[76] N. Roy, N. Saha, P. Humpolicek, and P. Saha, "Permeability and biocompatibility of novel medicated hydrogel wound dressings," Soft Materials, vol. 8, no. 4, pp. 338-357, 2010.

[77] E. Saljoughi, M. Sadrzadeh, and T. Mohammadi, "Effect of preparation variables on morphology and pure water permeation flux through asymmetric cellulose acetate membranes," Journal of Membrane Science, vol. 326, no. 2, pp. 627-634, 2009.

[78] M. M. Meier, L. A. Kanis, J. C. de Lima, A. T. N. Pires, and V. Soldi, "Poly(caprolactone triol) as plasticizer agent for cellulose acetate films: influence of the preparation procedure and plasticizer content on the physico-chemical properties," Polymers for Advanced Technologies, vol. 15, no. 10, pp. 593-600, 2004.

[79] R. Quintana, O. Persenaire, L. Bonnaud, and P. Dubois, "Recent advances in (reactive) melt processing of cellulose acetate and related biodegradable bio-compositions," Polymer Chemistry, vol. 3, no. 3, pp. 591-595, 2012.

[80] V. Sedlařík, N. Saha, I. Kuřitka, and P. Sáha, "Preparation and characterization of poly (vinyl alcohol)/lactic acid compounded polymeric films," International Journal of Polymer Analysis and Characterization, vol. 11, no. 4, pp. 253-270, 2006. 

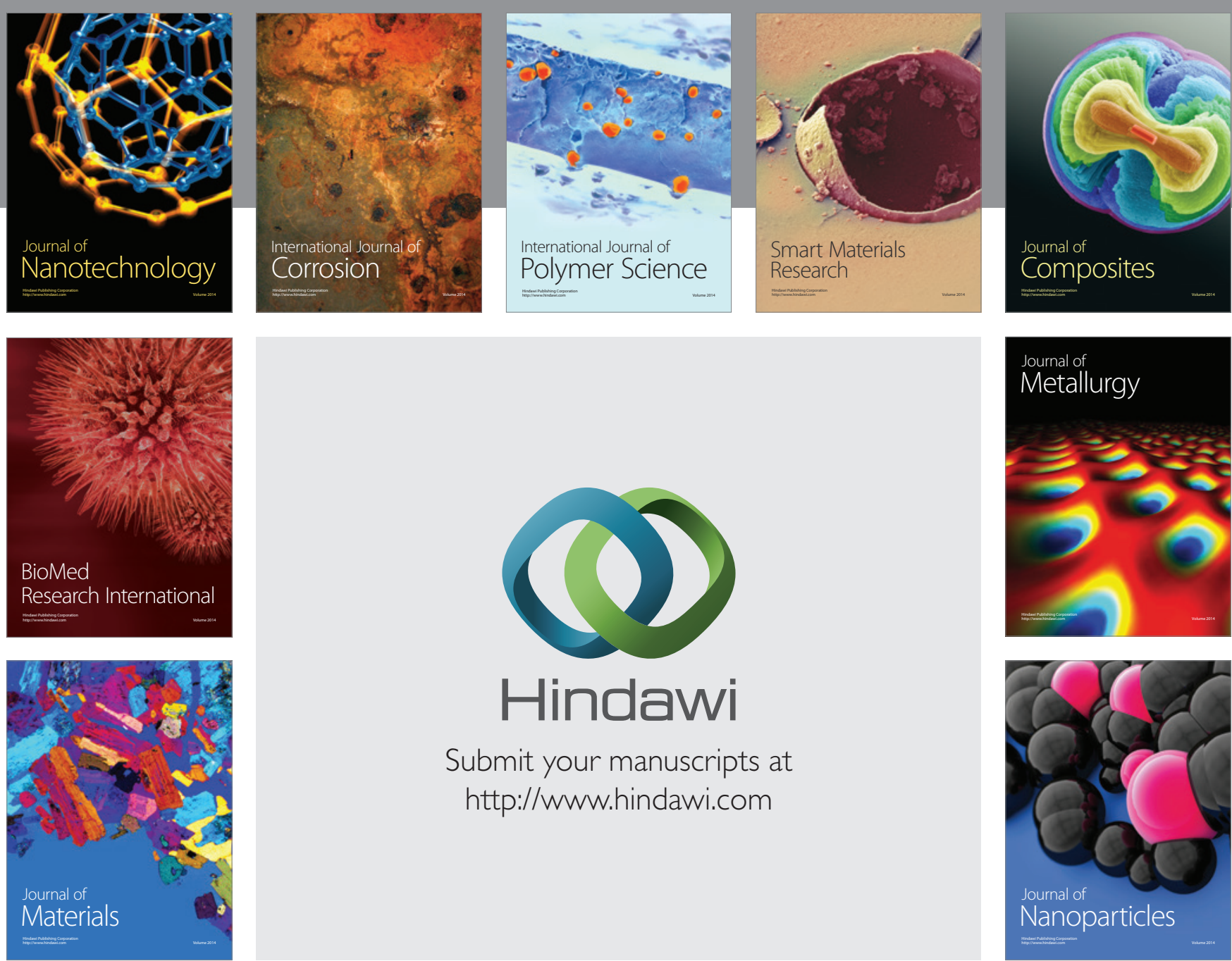

\section{Hindawi}

Submit your manuscripts at

http://www.hindawi.com

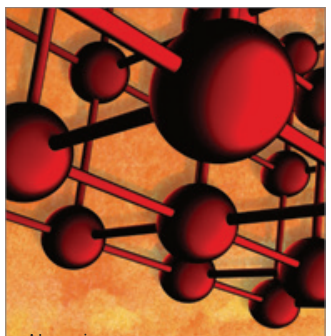

Materials Science and Engineering
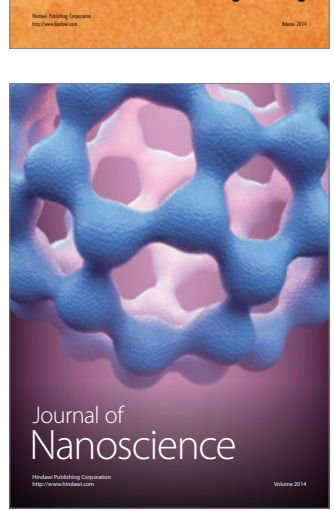
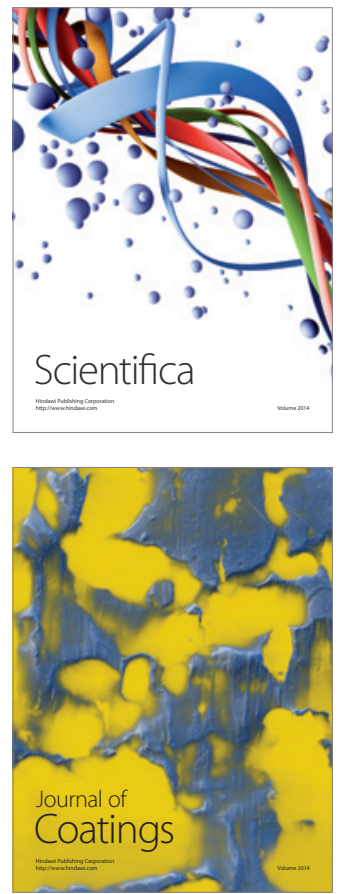
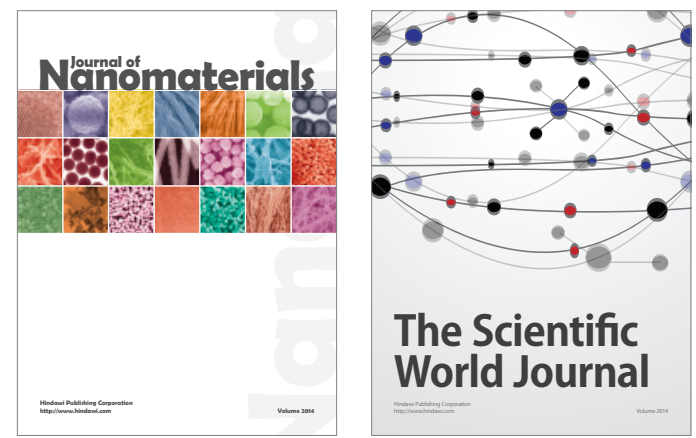

The Scientific World Journal
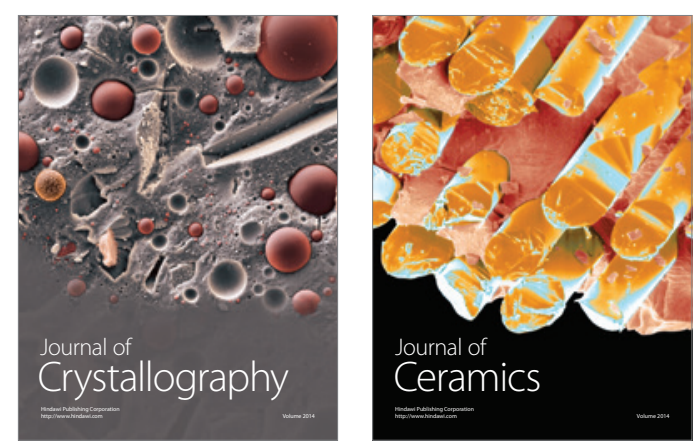
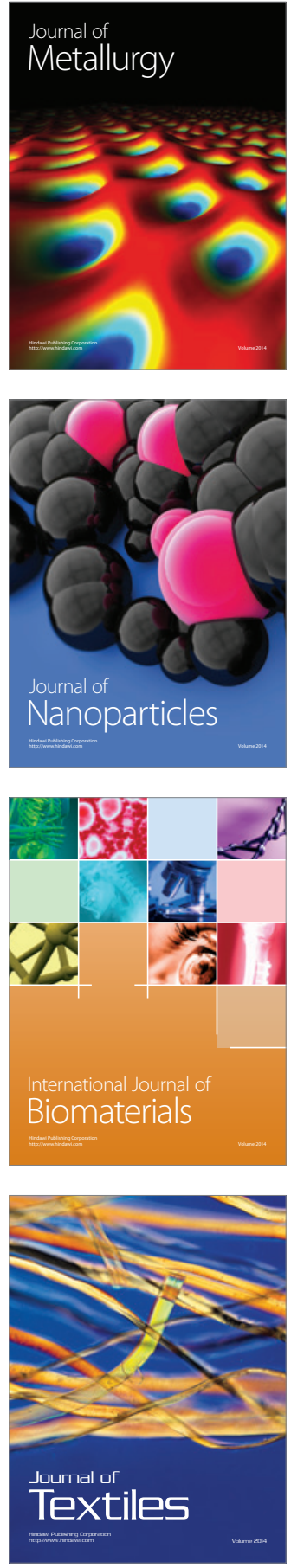